\title{
Growth phase dependent changes in the structure and protein composition of nucleoid in Escherichia coli
}

\author{
TALUKDER AliAzam ${ }^{1,3 *} \&$ ISHIHAMA Akira ${ }^{2,3}$ \\ ${ }^{1}$ Department of Microbiology, Jahangirnagar University, Dhaka 1342, Bangladesh; \\ ${ }^{2}$ Department of Molecular Genetics, National Institute of Genetics, Shizuoka 411-8540, Japan; \\ ${ }^{3}$ Micro-Nano Technology Research Center, Hosei University, Tokyo 184-0003, Japan
}

Received August 31, 2014; accepted January 6, 2015; published online July 24, 2015

\begin{abstract}
The genomic DNA of bacteria is highly compacted in a single or a few bodies known as nucleoids. Here, we have isolated Escherichia coli nucleoid by sucrose density gradient centrifugation. The sedimentation rates, structures as well as protein/DNA composition of isolated nucleoids were then compared under various growth phases. The nucleoid structures were found to undergo changes during the cell growth; i. e., the nucleoid structure in the stationary phase was more tightly compacted than that in the exponential phase. In addition to factor for inversion stimulation (Fis), histone-like nucleoid structuring protein (H-NS), heat-unstable nucleoid protein (HU) and integration host factor (IHF) here we have identified, three new candidates of $E$. coli nucleoid, namely DNA-binding protein from starved cells (Dps), host factor for phage Q $\beta$ (Hfq) and suppressor of $t d^{-}$phenotype A (StpA). Our results reveal that the major components of exponential phase nucleoid are Fis, HU, H-NS, StpA and Hfq, while Dps occupies more than half of the stationary phase nucleoid. It has been known for a while that Dps is the main nucleoid-associated protein at stationary phase. From these results and the prevailing information, we propose a model for growth phase dependent changes in the structure and protein composition of nucleoid in E. coli.
\end{abstract}

growth phase, sucrose gradient, bacterial nucleoid, DNA binding protein, DNA compaction

Citation: Talukder AA, Ishihama A. Growth phase dependent changes in the structure and protein composition of nucleoid in Escherichia coli. Sci China Life Sci, 2015, 58: 902-911, doi: 10.1007/s11427-015-4898-0

The chromosomes in the eukaryotic nucleus are compacted into the nucleosomes with histone proteins as the basic unit. However, in bacteria there is no such nucleosome, instead the DNA is organized into a nucleoid body with particular proteins in the cells [1,2]. In E. coli, the chromosome consists of 4.7 Mbp of DNA which, when extended, is about $1.5 \mathrm{~mm}$ long [3]. The chromosome is packaged into a nucleoid in a cell only $1 \mu \mathrm{m}$ long and hence mandates a highly ordered structure [4-10].

DNA is negatively supercoiled in vivo, and a number of nucleoid-associated proteins have been implicated in the organization of bacterial chromatin, with additional roles in

*Corresponding author (email: tunubj@yahoo.com) transcription, recombination, and replication [11-18]. In $E$. coli, the four most abundant nucleoid-associated proteins are factor for inversion stimulation (Fis), histone-like nucleoid structuring protein (H-NS), heat-unstable nucleoid protein (HU) and integration host factor (IHF) [19-25]. However, at present, a clear picture of how the E. coli nucleoid is organized is far from being complete. This may be due to insufficient documentation of the molecular structure and composition of $E$. coli nucleoid and its growth phase dependent variations.

In order to understand the overall configuration and physiological activities of the E. coli nucleoid under various growth phases and the role(s) of each nucleoid protein in gene expression, we had previously reported, a systematic 
comparison of the sequence recognition specificity and the DNA-binding affinities among twelve species of the nucleoid-associated proteins, including curved DNA-binding protein A (CbpA), curved DNA-binding protein B or right arm of the replication origin binding protein ( $\mathrm{CbpB}$ or $\mathrm{Rob}$ ), DNA-binding protein A (DnaA), DNA-binding protein from starved cells (Dps), Fis, host factor for phage $Q \beta$ (Hfq), H-NS, HU, inhibitor of chromosome initiation A (IciA), IHF, leucine-responsive regulatory protein (Lrp) and suppressor of $t d^{\top}$ phenotype A (StpA) [26]. The intracellular concentration and sub-cellular localization of these proteins were also determined previously [27-29]. Here we have employed Western immunoblot techniques for in vivo quantitative estimation of 10 nucleoid proteins including two species of RNA polymerase proteins, the core enzyme subunit $\alpha$ and the $\sigma 38$ subunit, after separation of cell lysates into nucleoid and cytosolic fractions by sucrose density gradient centrifugation. The results presented below clearly indicate the major components of exponential phase nucleoid are Fis, HU, H-NS, StpA and Hfq/IHF, while Dps occupies more than half of the stationary-phase nucleoid. Cellular abundance and variation of these proteins might be involved in the growth phase dependent changes in the structure of $E$. coli nucleoids.

\section{Materials and methods}

\subsection{Bacterial strain, growth conditions and determina- tion of the total number of cells}

The bacterial strain for analysis of DNA-binding proteins was the A-type lineage of E. coli W3110 (IN [ rrnD$r m E] r p h-1)$, which carries the intact forms of both $\sigma^{\mathrm{S}}$ and $\sigma^{\mathrm{F}}$ [30]. Cells were grown at $37^{\circ} \mathrm{C}$ under aeration in Luria broth (LB) medium. The growth was monitored by measuring the turbidity with a Klett-Summerson photometer. The culture conditions were fixed as follows: a few colonies from overnight cultures on LB agar plates were inoculated into $3 \mathrm{~mL}$ of fresh LB medium. At the cell density of 250 Klett units (the early-stationary phase), the culture was then diluted 1,000-fold by adding fresh LB medium and the culture growth was continued at $37^{\circ} \mathrm{C}$ at a constant shaking rate of 160 rotation per minute (rpm). Aliquots of the culture were taken at various time intervals as indicated in the text. The number of cells was counted with a Coulter Multisizer II (Coulter Electronics Limited, Northwell Drive, Luton, Beds, LU3 3RH, UK) as described previously.

\subsection{Preparation and isolation of nucleoid by sucrose density gradient centrifugation}

Preparation of nucleoids and their sucrose density gradient centrifugation run were performed according to the protocol devised by Kornberg et al. [31] and modified by Murphy

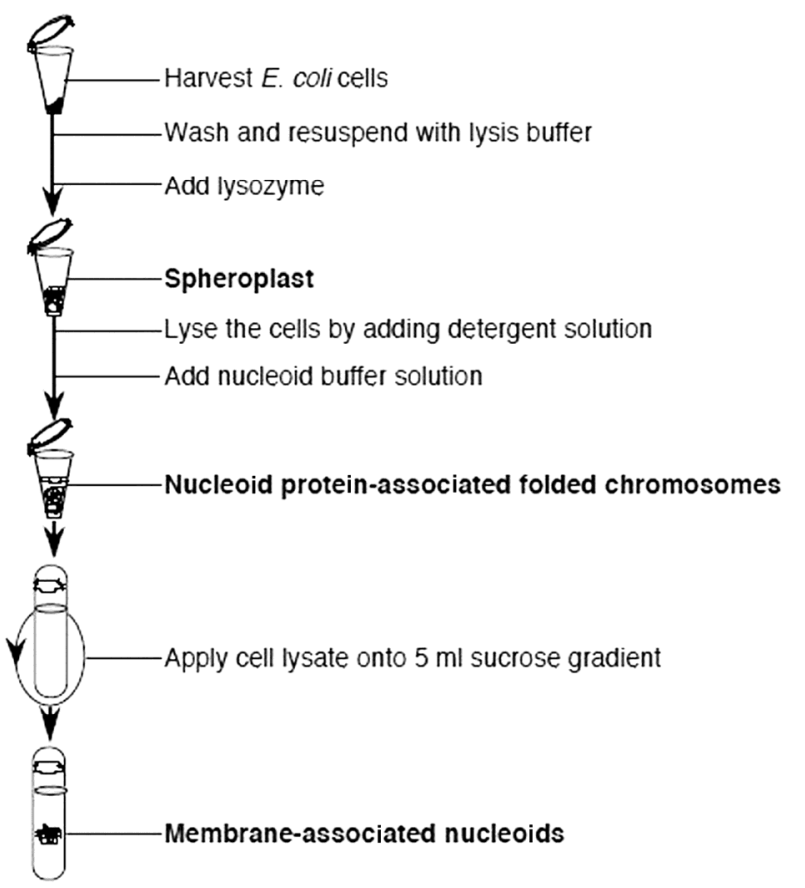

Figure 1 Schematic procedure for preparation and isolation of E. coli nucleoids. E. coli cells were cultured from exponential phase to early staitionary phases, harvested, prepared cell lysates and their nucleoids were separated from the whole cell extracts by sucrose density gradient centrifugation (see Materials and methods for detail). In brief, equal numbers of cells (each containing about $1.9 \times 10^{8}$ cells per $\mathrm{mL}$ ) were collected from exponential to early-stationary phases, diluted where necessary and hervested by centrifugation for $10 \mathrm{~min}$ at $1,000 \times g$ at $4^{\circ} \mathrm{C}$. Washed cells were resuspended with lysis buffer $\left(10 \mathrm{mmol} \mathrm{L}^{-1}\right.$ tris- $\mathrm{HCl}(\mathrm{pH} 8.2)$ at $0^{\circ} \mathrm{C} ; 0.1 \mathrm{~mol} \mathrm{~L}{ }^{-1}$ $\mathrm{NaCl} ; 20 \%(\mathrm{w} / \mathrm{v})$ Sucsore with $1.0 \mathrm{mmol} \mathrm{L}^{-1} \mathrm{NaN}_{3}$ ) and then added lysozyme $\left(4 \mathrm{mg} \mathrm{mL}^{-1}\right.$ in $0.2 \mathrm{~mol} \mathrm{~L}^{-1}$ Tris- $\mathrm{HCl}$ buffer $\left(\mathrm{pH} 8.2\right.$ at $0^{\circ} \mathrm{C}$ ) containing $50 \mathrm{mmol} \mathrm{L}^{-1}$ ethylene diamine tetraacetic acid (EDTA) and incubated the mixture for $40 \mathrm{~s}$ at $0^{\circ} \mathrm{C}$. Lysed the cells by adding detergent solution (1\% (w/v) Brij-58, 0.4\% (w/v) Deoxychlolate in 10 mmol L ${ }^{-1}$ EDTA containing $10 \mathrm{mmol} \mathrm{L}^{-1}$ spermidine $\mathrm{HCl}$ and $0.5 \mathrm{~mol} \mathrm{~L}^{-1}$ di-isopropylfluorophosphate) and kept mixture at $0^{\circ} \mathrm{C}$ for $7 \mathrm{~min}$. Nucleoid buffer solution (10 mmol L ${ }^{-1}$ Tris- $\mathrm{HCl}$ buffer $(\mathrm{pH} 7.8)$ at $0^{\circ} \mathrm{C}$ containing either $10 \mathrm{mmol} \mathrm{L}^{-1}$ $\mathrm{KCl}$ (Low salt nucleoid buffer for isolation of membrane-associated nucleoids) or 1,000 $\mathrm{mmol} \mathrm{L}^{-1} \mathrm{KCl}$ (High salt nucleoid buffer for membrane free nucleoids, data not shown), $1.0 \mathrm{mmol} \mathrm{L}{ }^{-1}$ EDTA, $0.2 \mathrm{mmol} \mathrm{L}^{-1}$ dithiothreitol, $1.0 \mathrm{mmol} \mathrm{L}^{-1}$ spermidine $\mathrm{HCl}$ ) was then added in the lysed cells and mixed gently. Applied cell lysate onto $5.0 \mathrm{~mL}$ sucrose gradient tube (Linear gradient was prepared in a plastic centrifuge tube with a increase from $12 \%$ to $60 \%$ sucrose in nucleoid buffer) and were then run at 7,000 $\times g$ at $4^{\circ} \mathrm{C}$ for $120 \mathrm{~min}$ in a Spinco SW50.1 rotor. Various fractions were collected from bottom to up-word of the gradient tube, mixed with $0.2 \mathrm{~mol} \mathrm{~L}^{-1}$ EDTA and stored at $4^{\circ} \mathrm{C}$ until further use.

and Zimmerman [32] (for details see Figure 1). Equal numbers of cells (each containing about $1.9 \times 10^{8}$ cells $\mathrm{mL}^{-1}$ ) were collected from exponential to early-stationary phases, diluted where necessary, gently treated with lysozyme and then lysed with detergents in low salt media containing spermidine. These low-salt spermidine nucleoids have much higher protein and RNA contents than the high-salt nucleoids and contain DNA-binding proteins. In our cell lysate preparation, we have used $400 \mu \mathrm{g}$ lysozyme per $\mathrm{mL}$ and 
chose to limit the exposure to lysozyme to $40 \mathrm{~s}$ at $0^{\circ} \mathrm{C}$. The mild lysozyme concentration gave efficient detergent lysis under the conditions employed, as judged by recovery of cellular DNA in a nucleoid fraction (see below). Linear $12 \%-60 \%$ sucrose gradients in $10 \mathrm{mmol} \mathrm{L}{ }^{-1}$ Tris- $\mathrm{HCl}(\mathrm{pH}$ 7.8 at $0^{\circ} \mathrm{C}$ ) containing $10 \mathrm{mmol} \mathrm{L}^{-1} \mathrm{KCl}, 1 \mathrm{mmol} \mathrm{L}^{-1}$ EDTA, $0.2 \mathrm{mmol} \mathrm{L}^{-1}$ dithiothreitol (DTT), $1 \mathrm{mmol} \mathrm{L}^{-1}$ spermidine $\mathrm{HCl}$ were formed in a cold room in $5 \mathrm{~mL}$ Ultraclear plastic centrifuge tubes $(13 \mathrm{~mm} \times 51 \mathrm{~mm}$, Beckman $)$ and were run at $7000 \times g$ at $4^{\circ} \mathrm{C}$ for $120 \mathrm{~min}$ in a Spinco SW50.1 rotor (the centrifugal force was reduced to $7,000 \times g$ ). Whole cell lysates from different growth phases were completely sedimented under these conditions. After the run, the tubes were placed against a dark background, illuminated with a high-intensity sharp light from the top and immediately photographed. The relative positions of each of the five independent nucleoids isolated from different growth phases were reproducible at different speeds and for longer runs (data not shown). The speed and duration of the runs used in this study were chosen in order to maintain the fastest moving band (nucleoids from the $6.0 \mathrm{~h}$ cultures) within the bottom of the gradient. Fractions (in an average $0.45 \mathrm{~mL}$ ) were collected from the bottom of each gradient and mixed with $20 \mu \mathrm{L}$ of $0.2 \mathrm{~mol} \mathrm{~L}^{-1}$ EDTA.

\subsection{Polyacrylamide gel electrophoresis and estimation of protein and DNA contents}

The sedimentation patterns of total proteins from isolated nucleoids were compared with those of other cell fractions by SDS-containing $15 \%$ polyacrylamide gel. Gels were stained with Coomassie brilliant blue (CBB). DNA was digested at $37^{\circ} \mathrm{C}$ for 30 min together with $20 \mu \mathrm{g}$ of RNaseA and $20 \mu \mathrm{g}$ of ProteinaseK per $\mathrm{mL}$. After digestion, DNA was purified by extraction with phenol/chloroform and then precipitated with ethanol. DNA and protein were measured from optical density at $280 \mathrm{~nm}$ and absorbance of Bradford reagent (Bio-Rad Protein Assay Kit (Bio-Rad), USA), respectively.

\subsection{Preparation of nucleoid for microscopic analysis}

The nucleoid bands in the gradients were collected gently with a well-mounted pipette tip and transferred into Eppendrof and fixed with $0.1 \%$ Glutaraldehyde (final concentration). The fixed nucleoids $(5 \mu \mathrm{L})$ were dropped into the well of a 10-well multitest microscope slide $(76 \mathrm{~mm} \times 26 \mathrm{~mm}$ with $24 \mathrm{~mm} \times 60 \mathrm{~mm}$ coverslip; Matsunami glass Ind., Ltd., Japan) and air dried at $27^{\circ} \mathrm{C}$. The nucleoids were stained with $5 \mu \mathrm{L}$ 4',6-diamidino-2-phenylindole dihydrochloride (DAPI) solution $\left(5 \mu \mathrm{g} \mathrm{mL} \mathrm{m}^{-1}\right)$ which bind specifically to DNA, using the method developed by Hiraga et al. [33]. Average nucleoids area was estimated as described previously [34].

\subsection{Purification of nucleoid proteins and preparation of antibodies}

All ten nucleoid proteins, RpoA, $\sigma 38$, CbpB (Rob), Dps, Fis, Hfq, H-NS, HU, IHF, and StpA, were overexpressed with pGEMX180, pETF, pMK19, pDPS1, pRJ1077, pHFQ607, pHOP11, pLhupAhupB, pSA5hiphimA, and pT7stpA, respectively, and purified to apparent homogeneity as described previously [26]. Antibodies against each protein were produced in rabbits by injecting the purified proteins as previously described [35].

\subsection{Quantitative western immunoblot analysis}

For the measurement of each of the ten nucleoid proteins in E. coli W3110A (FIN [rrnD-rmE]rph-1) nucleoid and cytosolic fractions, a quantitative Western immunoblot analysis was employed using the polyclonal anti-RpoA, anti- $\sigma 38$, anti-CbpB (anti-Rob), anti-Dps, anti-Fis, anti-Hfq, anti-H-NS, anti-HU, anti-IHF, and anti-StpA antibodies [29,35]. In brief, either nucleoid or cytosolic fractions were treated with a sodium dodecyl sulfate (SDS) sample buffer $\left(50 \mathrm{mmol} \mathrm{L}^{-1}\right.$ Tris-HCl [pH 6.8], 2\% SDS, 1\% 2-mercaptoethanol, 10\% glycerol, $0.025 \%$ bromophenol blue) and separated on SDS-15\% polyacrylamide gels. Protein in the gel was directly electroblotted onto polyvinylidene difluoride (PVDF) membranes (Nippon Genetics, Japan). Blots were blocked overnight at $4{ }^{\circ} \mathrm{C}$ in $3 \%$ bovine serum albumin (BSA) in phosphate-buffered saline (PBS), probed with the specific antibodies against each protein, washed with $0.5 \%$ Tween 20 in PBS, and incubated with goat anti-rabbit immunoglobulin G conjugated with hydroxyperoxidase (Cappel, USA). The blots were developed with electrogenerated chemiluminescence (ECL) Western blotting detection reagents (Amersham, UK) and chemiluminescence was quantitated with a lumino-image analyzer LAS-1000 (Fuji, Japan).

For accurate measurement of the levels of each of the nucleoid proteins, we took care in the followings: (i) the protein range was determined for each protein, where the linear relationship existed between the protein concentration and the immunostaining intensity; (ii) the determination was carried out using several volumes of cell lysates, which contained the test proteins at the concentration range determined as above; (iii) the standard samples of known concentrations were always included in the assays; and (iv) the determination was repeated at least three times for each DNA-binding protein.

\section{Results and discussion}

\subsection{Isolation and composition of $E$. coli nucleoids}

In our previous study, we performed intracellular localiza- 
tion of $E$. coli 16 -species of DNA-binding proteins by indirect immunofluorescence microscopy [28]. We found two types of localization within the $E$. coli nucleoid. One group of proteins, including the major nucleoid-structural proteins, Dps, H-NS, HU, IHF, and StpA is distributed uniformly within the entire nucleoid, but the other group of proteins showed an irregular distribution, forming immuno-stained spots or clumps [28]. To check whether these immuno-localization patterns are consistent, we decided to examine the nucleoid structures and compositions by sucrose density gradient centrifugation. At first, we checked several experimental conditions to deduce the most suitable procedure for isolation of $E$. coli nucleoid from the whole cell extracts. Nucleoids are generally released from cells in a Tris-EDTA buffer by treatment with lysozyme, followed by application of one or several detergents (Brij-58, Deoxychlolate, Np-40). After examining several parameters including nucleoid buffer composition (different concentrations of salt, lysozyme, detergent, spermidine), reaction conditions for preparation of cell lysates, different centrifugation speeds and times, we developed a procedure for the isolation of nucleoids in a single visible fraction from the sucrose density gradient centrifugation (Figure 1). Our established method was mainly based on nucleoid isolation procedures described previously by Kornberg et al. [31], and modified by Murphy and Zimmerman [32].

Cells were cultured from exponential to early-stationary phases $(2.5,3,4,5,6 \mathrm{~h})$ and harvested for preparation of nucleoid as described in Materials and methods. The positions of the E. coli membrane-associated nucleoids are shown in Figure 2A. The tubes containing a single visible band are referred to as nucleoid fraction. Interestingly, sedimentation patterns of nucleoids were different from exponential phase to early-stationary phase cultures; from slow to rapid sedimentation, which indicate chromosome compaction/condensation occurred gradually from the exponential phase to the stationary phase (Figure 2A (a-e)). Large thick arrows in each of the five drawing tubes indicate the position and direction of sedimentation of nucleoid fractions (Figure 2A, bottom panel). The sedimentation runs in various samples were performed with different speeds and for different lengths of time, but the visible bands of each of the 5 nucleoids retained their relative positions in

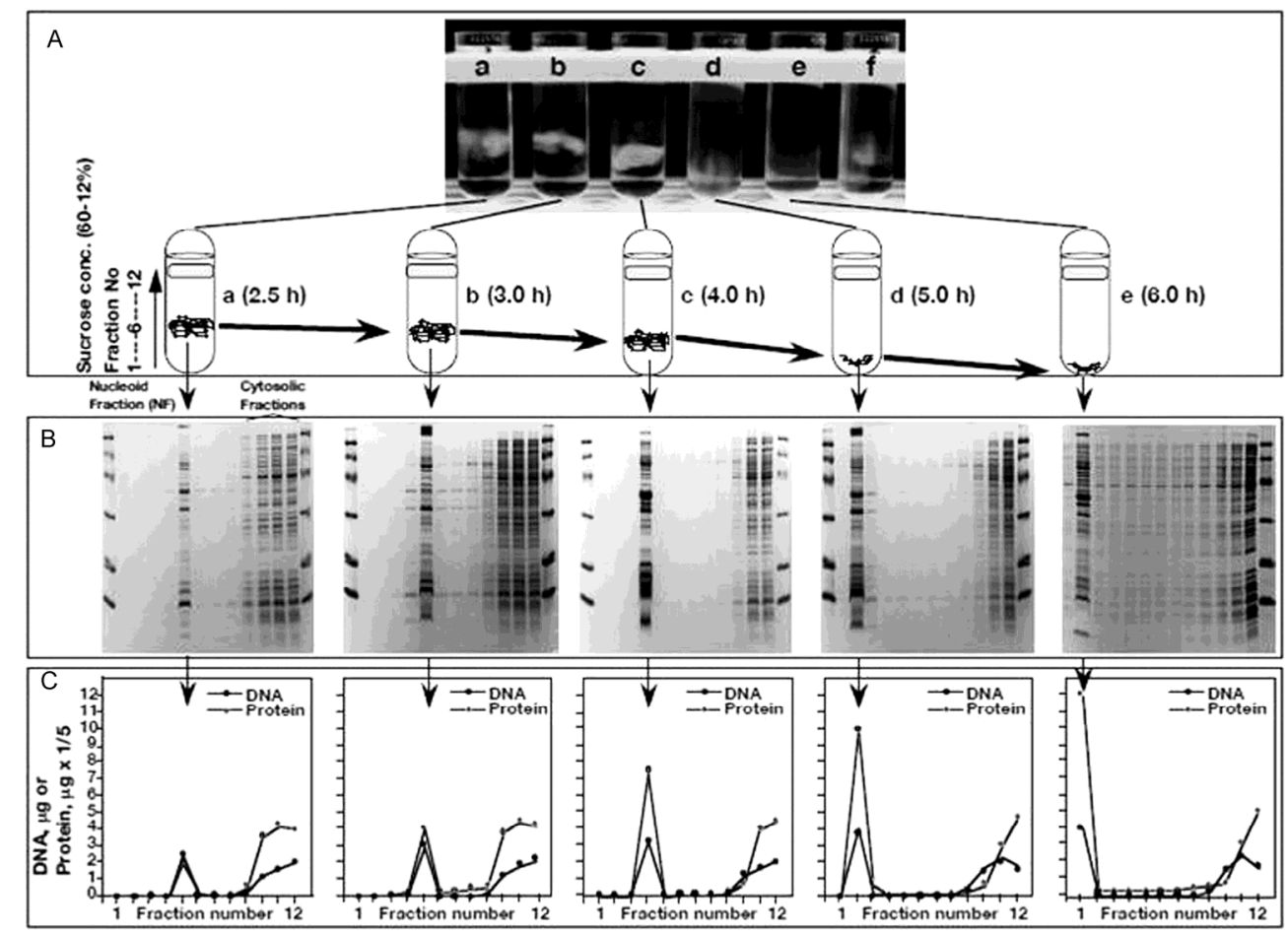

Figure 2 Sucrose density gradient centrifugation patterns of $E$. coli cell lysates. A, Sucrose density gradient centrifugation of isolated nucleoids. Tubes a-e represent nucleoids fractions which were isolated from $2.5,3,4,5$, and $6 \mathrm{~h}$ culture, respectively, while, tube f represents nucleoids isolated from the mixed cell lysates of 2.5 and $6 \mathrm{~h}$ culture. Large thick arrows in each of the five drawing tubes (bottom panel represented from left to right) indicate the position and direction of sedimentation of isolated nucleoids. B, Electrophoresis patterns of total proteins from isolated nucleoids were compared with those of other cell fractions on a SDS-15\% polyacrylamide gel. $5 \mu \mathrm{L}$ of each of the 12 fractions in different growth phases were applied to lanes $2-13$ (except $2 \mu \mathrm{L}$ in lane 3 of $5 \mathrm{~h}$ nucleoid fraction, and $1 \mu \mathrm{L}$ in lane 2 of $6 \mathrm{~h}$ nucleoid fraction). Lanes 1 and 14 of each of the five gels represent the standard molecular mass markers (molecular mass values in $\mathrm{kD}$ shown from top to bottom: phosphorylase b, $97.4 \mathrm{kD}$; bovine serum albumin, $66.2 \mathrm{kD}$; ovalbumin, $45.0 \mathrm{kD}$; carbonic anhydrase, $31.0 \mathrm{kD}$; soybean trypsin inhibitor, $21.5 \mathrm{kD}$; and lysozyme, $14.4 \mathrm{kD})$ except lane 1 in $6 \mathrm{~h}(5 \mu \mathrm{L}$ of washed fraction). Gels were stained with Coomassie brilliant blue (CBB). Small thin arrows indicate nucleoid fractions, which were isolated from different cell lysates. C, DNA and protein contents in the sucrose density gradient fractions collected from bottom upward (represented from left to right). Total DNA and protein content were measured from optical density at $280 \mathrm{~nm}$ and absorbance of Bradford reagent (Bio-Rad Protein Assay Kit (Bio-Rad)), respectively. 
the gradient (data not shown). Furthermore, we checked whether the sedimentation patterns of two distinct growth phases were reproducible, cell lysates were prepared from both the exponential $(2.5 \mathrm{~h}$ culture $)$ and early-stationary phases ( $6 \mathrm{~h}$ culture) and loading equal volume $(500 \mu \mathrm{L})$ on top of the gradient. As expected, sedimentation pattern of each nucleoid was different and stable at the same positions as seen previously (compare Figure $2 \mathrm{~A}(\mathrm{a})$ and $\mathrm{A}(\mathrm{e})$ with $\mathrm{A}(\mathrm{f})$ ). The results again indicated that the chromosome compaction/condensation occurred gradually from exponential phase to stationary phase where DNA superhelicity decreases [36,37].

In order to determine whether these bands corresponded to the nucleic acid-protein complexes that putative nucleoids are presumed to be, the gradients were collected from the bottom in 12 equal volume fractions except nucleoid fractions in each of 5 growth conditions (see below). Protein expression patterns are shown in Figure 2B. Single sharp nucleoid fractions from different cell lysates are indicated by an arrow in each of the 5 gels (for example, lane 6 in 2.5 h culture). Lanes 10-13 represent the cytosolic fractions. The total volume of exponentially growing nucleoid fractions was $800 \mu \mathrm{L}$. This volume reduced gradually and reached $250 \mu \mathrm{L}$ in early-stationary phase (data not shown). Consequently, protein concentration was found to increase from 2 to $12 \mu \mathrm{g} \mu \mathrm{L}^{-1}$ from exponential phase to early-stationary phase, respectively (Figure 2C). An average total protein mass of isolated nucleoid and cytosolic fractions were determined to be 2,527 and 5,343 $\mu$ g, respectively (see Table 1 for detail).

The relative composition and cellular distribution ratio of protein and DNA in whole cells, nucleoids, and cytosolic fractions were estimated as shown in Table 1. About $28 \%-45 \%$ and $52 \%-71 \%$ of the cellular DNA were recovered from the nucleoids and cytosolic fractions, respectively. In the exponentially growing culture, the total DNA concentration was $868 \mu \mathrm{g}$. However, this ratio changed gradually and reached $723 \mu \mathrm{g}$ at the early-stationary phase (Table 1). Our results are consistent with the results published previously by Åkerlurd et al. [38] flow cytometric observations clearly indicated that in rich media, both cell size and DNA content started to decrease when cultures left the exponential phase. The fractions comprising both the nucleoid and cytosolic peaks have a protein/DNA ratio of roughly $10 / 1$ (Table 1 ). Although the ratio was about two fold higher compared the protein/DNA ratio reported previously [32]. The possible reason of such variations might also be due to the different conditions were employed for isolation of nucleoids from the whole cell lysates. In addition to protein and DNA, crude nucleoids contain huge amounts of RNA. This RNA was efficiently degraded within the first few minutes of the RNaseA digestion (data not shown).

\subsection{Growth phase dependent changes in the structure and composition of $E$. coli nucleoid}

Stationary phase nucleoid is much more compacted than that in the exponential phase in an intact cell [28]. We decided to examine the structures of $E$. coli nucleoid in different growth phases by fluorescence microscopy. Nucleoids were isolated and fixed with Glutaraldehyde as described in Materials and methods. Our pictures of the individual nucleoids are shown in Figure 3. The fluorescence was more extended for the exponential growing nucleoids whereas the stationary phase nucleoids were relatively compact. The average area of the nucleoids decreased about two-fold in the early-stationary phase, from 2.2 to $1.3 \mu^{2}$ (Figure 3B). Sedimentation profiles and microscopic studies of DAPI stained nucleoids have previously been reported [32,36,39]. Microscopic appearance of the nucleoids was found to be consistent with the sedimentation profiles (Figure 2). Moreover, Kim et al. [40] found similar results by atomic force microscopy (AFM). Therefore, we assumed that the chromosome compaction/condensation occurs gradually from exponential phase to stationary phase.

During rapid growth in rich medium (doubling time, around $30 \mathrm{~min}$ ) exponential phase cells had a higher percentage of multiple-node nucleoids than stationary phase cells (Figure 3A). A node may have nothing to do with DNA replication; it may merely be a locus at which the DNA is gathered when $1.5 \mathrm{~mm}$ of DNA is compacted into a

Table 1 Protein and DNA composition of whole cell extracts and isolated nucleoids in E. coli ${ }^{\text {a) }}$

\begin{tabular}{|c|c|c|c|c|c|c|c|c|c|c|c|c|c|c|c|c|c|c|c|}
\hline \multirow{2}{*}{\multicolumn{2}{|c|}{ Incubation time }} & \multicolumn{4}{|c|}{ Protein $(\mu \mathrm{g})$} & \multicolumn{3}{|c|}{ PDR $(\%)$} & \multicolumn{4}{|c|}{ DNA $(\mu \mathrm{g})$} & \multicolumn{3}{|c|}{ DDR $(\%)$} & \multicolumn{4}{|c|}{ Protein/DNA ratio } \\
\hline & & \multirow{2}{*}{$\begin{array}{l}\text { WCE } \\
7294\end{array}$} & \multirow{2}{*}{$\begin{array}{l}\mathrm{OH} \\
114\end{array}$} & \multirow{2}{*}{$\begin{array}{c}\text { NF } \\
1600\end{array}$} & \multirow{2}{*}{$\frac{\mathrm{CF}}{5580}$} & \multirow{2}{*}{$\begin{array}{c}\mathrm{OH} \\
2\end{array}$} & \multirow{2}{*}{$\frac{N F}{22}$} & \multirow{2}{*}{$\begin{array}{r}\mathrm{CF} \\
76\end{array}$} & \multirow{2}{*}{$\begin{array}{l}\text { WCE } \\
868\end{array}$} & \multirow{2}{*}{$\begin{array}{c}\mathrm{OH} \\
26\end{array}$} & \multirow{2}{*}{$\begin{array}{l}\mathrm{NF} \\
392\end{array}$} & \multirow{2}{*}{$\begin{array}{l}\mathrm{CF} \\
450\end{array}$} & \multirow{2}{*}{$\begin{array}{c}\mathrm{OH} \\
3\end{array}$} & \multirow{2}{*}{$\begin{array}{c}\mathrm{NF} \\
45\end{array}$} & \multirow{2}{*}{$\begin{array}{r}\mathrm{CF} \\
52\end{array}$} & \multirow{2}{*}{$\begin{array}{c}\text { WCE } \\
8.4\end{array}$} & \multirow{2}{*}{$\begin{array}{c}\mathrm{OH} \\
4.4\end{array}$} & \multirow{2}{*}{$\begin{array}{l}\mathrm{NF} \\
4.1\end{array}$} & \multirow{2}{*}{$\begin{array}{c}\mathrm{CF} \\
12.4\end{array}$} \\
\hline 1) & $2.5 \mathrm{~h}$ & & & & & & & & & & & & & & & & & & \\
\hline 2) & $3.0 \mathrm{~h}$ & 8534 & 599 & 2000 & 5935 & 7 & 23 & 70 & 799 & 15 & 300 & 484 & 2 & 38 & 60 & 10.7 & 40 & 6.7 & 12.3 \\
\hline 3) & $4.0 \mathrm{~h}$ & 8525 & 360 & 3000 & 5165 & 4 & 35 & 61 & 730 & 7 & 260 & 463 & 1 & 36 & 63 & 11.7 & 51 & 11.5 & 11.2 \\
\hline 4) & $5.0 \mathrm{~h}$ & 8718 & 280 & 3150 & 5288 & 3 & 36 & 61 & 731 & 8 & 236 & 487 & 1 & 32 & 67 & 11.9 & 35 & 13.3 & 10.9 \\
\hline 5) & $6.0 \mathrm{~h}$ & 9218 & 990 & 3000 & 5228 & 10 & 33 & 57 & 723 & 8 & 200 & 515 & 1 & 28 & 71 & 12.7 & 124 & 15.0 & 10.2 \\
\hline \multicolumn{2}{|c|}{ Average } & 8297 & 428 & 2527 & 5343 & 5 & 30 & 65 & 768 & 11 & 279 & 478 & 1.4 & 36.2 & 62.5 & 10.9 & 61 & 9.9 & 11.2 \\
\hline
\end{tabular}

a) PDR, protein distribution ratio; DDR, DNA distribution ratio; WCE, whole cell extracts; $\mathrm{OH}$, esent the value of total 7 fraction except NF (1) and CF (4) as shown in Figure 2B,2C); NF, Nucleoid fraction; CF, Cytosolic fractions. 

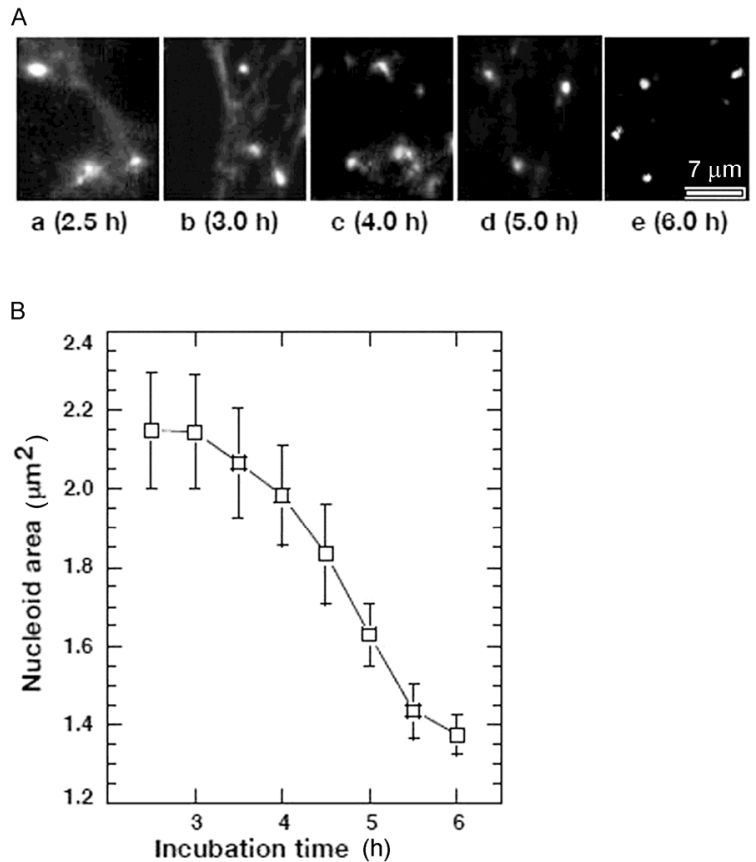

Figure 3 Fluorescence micrographs of isolated nucleoids. The nucleoid bands from the sucrose gradients were gently collected, washed, fixed, stained with DAPI and micrographed as described in the Materials and methods. Growth phase-dependent variations in the compaction states of isolated nucleoids in $E$. coli were shown from the left to right. A, Columns a-e represent nucleoid structures which were isolated from $2.5,3,4,5$, and $6 \mathrm{~h}$ culture, respectively. B, Effects of growth phase on the apparent size of compact nucleoids. Average nucleoid areas were determined from A. Error bar represents $\bar{x} \pm \mathrm{SD}$.

1-2 $\mu \mathrm{m}$ cell [3]. Our data, however, suggest that node structure is dynamic and coupled with growth phases, thus may reflect changes in DNA topology.

\subsection{Identification and characterization of nucleoid proteins}

Our next attempt was to identify the proteins which are associated with E. coli nucleoids. Protein expression patterns from nucleoid fractions were compared with those of cytosolic fractions by SDS-polyacrylamide gel electrophoresis as shown in Figure 4. In lanes 2 and 3, we had applied 5 and $1 \mu \mathrm{L}$ nucleoid fraction, isolated from exponential and early-stationary phase cultures, respectively. The same but equal volume $(2.5 \mu \mathrm{L})$ of both nucleoids fractions were applied in lanes 5 and 6 ; each lane contains 5 and $30 \mu \mathrm{g}$ proteins which were associated with 1.23 and $2.0 \mu \mathrm{g}$ DNA, respectively. On the other hand, lanes 8 and 9 corresponded to the cytosolic fractions of exponential and early-stationary phase, containing 10.0 and $12.5 \mu \mathrm{g}$ proteins associated with 1.0 and $0.83 \mu \mathrm{g}$ of DNA. It is clear that the RNA polymerase components $\left(\beta, \beta^{\prime}\right.$, and $\left.\alpha\right)$ are associated with the nucleoids fractions (compare lanes 4 and 7 with lanes 5 and 6). Upon reaching the cell at early-stationary phase (at around

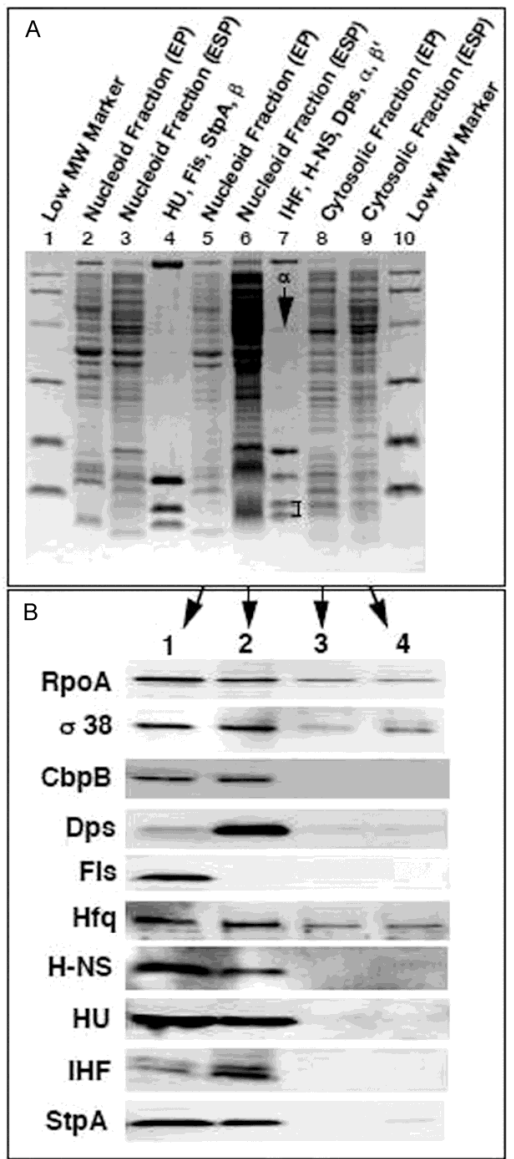

Figure 4 Growth phase-dependent variations in the intracellular levels of ten nucleoid proteins in E. coli. A, Electrophoresis patterns of isolated nucleoids and cytosolic fractions from exponential and early-stationary phase cultures were compared with those of other known proteins on a SDS-15\% polyacrylamide gel. Lanes 1 and 10, standard molecular mass markers as described in the legend of Figure 2B. Lanes 2 and 3, represent nucleoid fractions isolated from exponential and early-stationary phase cultures, which correspond to 10 and $15 \mu \mathrm{g}$ proteins, respectively. Lane 4 , known protein (represented from bottom to top), HU (9.4 kD), Fis (11.2 kD), StpA (15.3 kD), and $\beta$ subunit (150 kD) of RNA polymerase. Lanes, 5 and 6 represent the equal volume $(2.5 \mu \mathrm{L})$ of exponential and early-stationary phase nucleoid fractions, respectively, as described in the text. Lane 7, known protein (represented from bottom to top), IHF (heterodimer, 11.2 and $10.7 \mathrm{kD}), \mathrm{H}-\mathrm{NS}(15.4 \mathrm{kD}), \mathrm{Dps}(19.0 \mathrm{kD}), \alpha(37.5 \mathrm{kD}$, indicates by arrow-head) and $\beta^{\prime}(155 \mathrm{kD})$ subunits of RNA polymerase. Lanes, 8 and 9 represent the equal volume $(2.5 \mu \mathrm{L})$ of exponential and early-stationary phase cytosolic fractions, respectively. Gels were stained with Coomassie brilliant blue (CBB). B, Growth phase-dependent variation of ten-nucleoid proteins. For quantification of each of the ten-nucleoid proteins by Western blotting, aliquots of each of the 4 fractions (indicated by arrows (lanes 1 and 2 represent exponential phase and early stationary phase nucleoid fractions, respectively, and lanes 3 and 4 represent exponential phase and early stationary phase cytosolic fractions, respectively)) containing either $1 \mu \mathrm{g}$ for Dps, Fis, H-NS, HU, IHF or $4 \mu \mathrm{g}$ for RpoA, $\sigma 38$, CbpB (Rob), Hfq, and StpA were applied to lanes $1-4$ of the SDS-containing, $15 \%$ polyacrylamide gels. Proteins were Electro-blotted onto PVSF membranes. The blots were probed (represented from top to bottom) with anti-RpoA, anti- $\sigma 38$, anti-CbpB or anti-Rob, anti-Dps, anti-Fis, anti-Hfq, anti-H-NS, anti-HU, anti-IHF, and anti-StpA antibodies. After immuno-staining, the intensity of stained bands (chemiluminescence) was quantitated with a lumino-image analyzer LAS-1000 (Fuji, Japan). For increased accuracy of calculation of proteins, the Western blot analysis was repeated at least three times for all the samples. 
$6.0 \mathrm{~h}$ cultures in lane 6), several stationary-phase specific proteins were identified, concomitant with the decrease or disappearance of some growth-related proteins, like HU, H-NS, or StpA (compare lane 5 with lane 6). Dps and IHF were detectable in the early-stationary phase nucleoid fraction (compare lane 6 with lanes 5 and 7). As expected, exponentially abundant proteins $\mathrm{HU}, \mathrm{StpA}$, and H-NS were seen in the nucleoid fraction of exponential growing cultures. It was reported that Fis is a major component of the E. coli nucleoid and is present only in the growing phase cultures $[18,26]$. However, under the conditions employed here by CBB staining, we could not detect Fis in nucleoid fractions (Figure 4A). The nucleoid components were analyzed further by quantitative Western immunoblot analysis as shown below.

For the measurement of the relative distribution ratio of each of the ten-nucleoid proteins from E. coli, all these proteins were expressed at high levels using the respective cloned genes and purified to apparent homogeneity [26]. Polyclonal antibodies were raised in rabbits against the purified proteins (Table 2). The comparative Western immunoblot patterns of ten-nucleoid proteins are shown in Figure 4B. Among them, the intracellular accumulation patterns were different under different growth phases. The five most abundant proteins, Fis, Hfq, H-NS, HU and StpA were higher in exponential phase nucleoid fraction compared to that of nucleoid fraction isolated from the early-stationary phase culture (compare lane 1 with lane 2 in Figure 4B). The level of Dps and IHF were maximum at the stationary phase, while Fis was undetectable at this stage of growth. In addition to Hfq protein, significant amount of RNA polymerase components, RpoA and $\sigma 38$ were found not only in the nucleoid fractions but also in the cytosolic fractions.

Next we estimated the total amount of each of the ten proteins are shown in Figure 5A. A minimum of

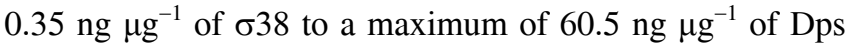
protein was detected under the condition employed here. The total amount of the 10 nucleoid proteins estimated in this study from the nucleoid and cytosolic fractions was 112 and $4.5 \mathrm{ng}$, respectively, during the exponential phase. A similar partitioning of these proteins was also estimated in the early stationary phase (Figure 5A). The relative distribution ratio among 10 proteins are shown in Figure 5B. On an average, about $95 \%$ proteins were associated with the nucleoid fractions of both phases. Almost $100 \%$ of CbpB, Fis, H-NS, HU, IHF and StpA were associated with the nucleoid

Table 2 Purification of E. coli nucleoid and preparation of antibodies

\begin{tabular}{llll}
\hline Protein & Plasmid for expression & Plasmid source & Antibodies \\
\hline CbpB & pMK19 & Mizuno Takeshi (Nagoya) \\
Dps & pDPS1 & This laboratory & This laboratory \\
Fis & pRJ1077 & Johnson Rick Carl (Los Angeles) \\
Hfq & pHFQ607 & This laboratory & This laboratory \\
H-NS & pHOP11 & Mizuno Takeshi (Nagoya) \\
HU & pLhupAhupB & Goshima Naoki (Hiroshima) \\
IHF & pSA5hiphimA & Oppenheim Amos B (Jerusalem) \\
StpA & pT7stpA & Belfort Marlene (Albany) \\
RNA polymerase $\alpha$ subunit & pGEMX180 & This laboratory & This laboratory \\
RNA polymerase $\sigma 38$ subunit & pETF & This laboratory & This laboratory \\
\hline
\end{tabular}
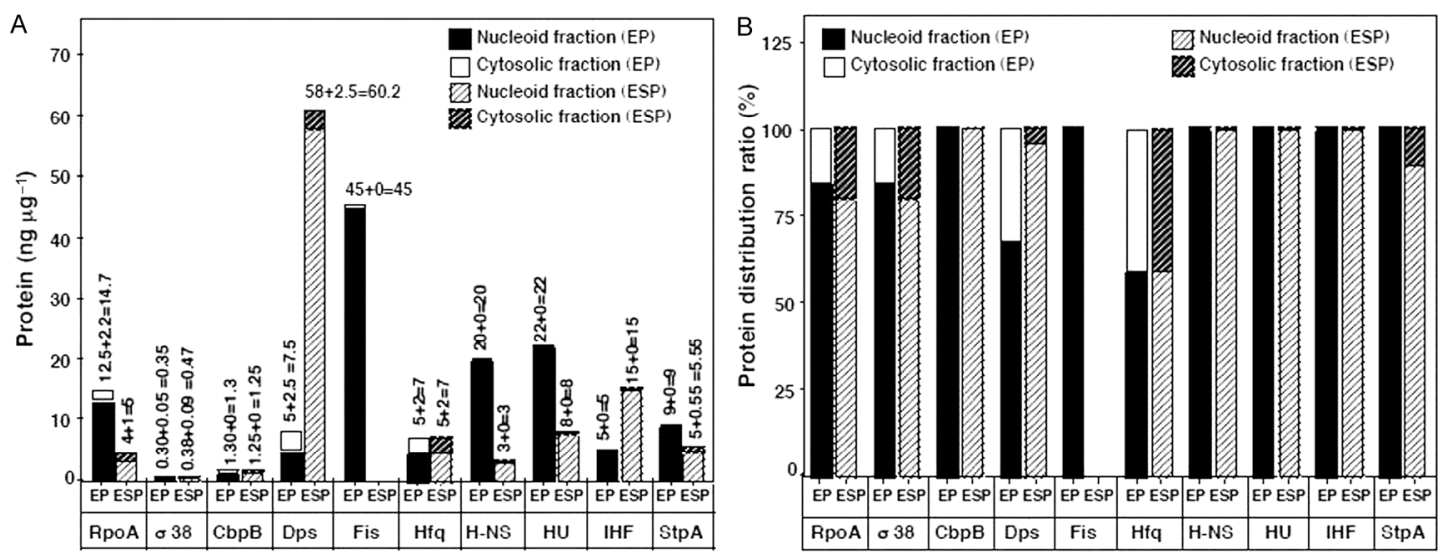

Figure 5 Growth phase-dependent variation in the intracellular distributions of ten-nucleoid proteins in E. coli. The measurement of each nucleoid protein was carried out as described in Figure 4. A, Total amounts of each protein (ng $\left.\mu \mathrm{g}^{-1}\right)$ at two distinct growth phases are shown; EP, exponential phase; ESP, early stationary phase. B, Percentage distribution ratios among the ten-nucleoid proteins, which were estimated from nucleoid and cytosolic fractions of exponential and early-stationary phase cultures, respectively. 
fractions isolated from exponential growing cultures. Levels of $\sigma 38$, RpoA and Hfq in the cytosolic fractions were $14 \%$, $15 \%$, and $30 \%$, respectively (Figure $5 \mathrm{~B}$ ).

Finally, here, we are proposing a model for growthcoupled changes in the structure and protein composition of E. coli nucleoid as shown in Figure 6. Our prediction of nucleoid composition is, however, based on the assumption that all the nucleoid proteins we have analyzed here are associated with the DNA (top inside circles of both growth phases). The percentage distribution ratios, in order of abundance, in the exponentially growing nucleoid are: Fis (40\%), HU (20\%), H-NS (18\%), StpA (8\%), Hfq/IHF/Dps (4\% of each protein), and $\mathrm{CbpB}(1 \%)$, while those in the early-stationary phase are Dps (61\%), IHF (16\%), HU (8\%), StpA (6\%), Hfq (5\%), H-NS (3\%), CbpB (1\%), and Fis $(0 \%)$. Thus the major structural components of the nucleoid (DNA with nucleoid associated proteins) changes from Fis, HU, H-NS, and StpA (and Hfq) in the exponential growing phase to Dps and IHF in the early stationary phase. These structural proteins influence the transcriptional level of sets of genes depending on their DNA-binding sites relative to the RNA polymerase-binding sites $[14,15]$. In addition of nucleoid-associated proteins (NAPs), some other changes were also found when cell reaches to stationary phase. Cell shape/size or cytoplasmic volume decreased, concomitantly, increased in cell wall composition [27]. In stationary phase, 4-5 layers of peptidoglycan were found compared to only 2-3 in exponential phase are represented by outer thick (top right) and thin (top left) circles, respectively, in Figure 6 [16]. This change might be involved to protect cytoplasmic components including nucleoid from various stresses created by stationary growth phase. Furthermore, increased stationary phase-specific gene expression levels of $\sigma^{\mathrm{S}}$ (Figure 4B), which directs the expression of more than 100 genes including $d p s$ and other stress-specifie genes, concomitantly, decreased other exponential growth related genes expression like rRNA, tRNA, fis $[16,27,28]$. Upon entry into the stationary phase, the $E$. coli nucleoid becomes compact and DNA superhelicity decreases (Figures 2-4) [14]. Our study clearly indicated that, either association of two stationary-phase proteins, Dps and IHF, or the decrease in Fis, $\mathrm{HU}, \mathrm{H}-\mathrm{NS}$, StpA and Hfq level must be involved in this process of DNA compaction [14,27,28,40].

In this study, we have first identified 3 proteins, Hfq, StpA and Dps from E. coli nucleoids. These proteins were previously reported to bind to either DNA or RNA [26,41-46]. Hfq was identified as a host factor, designated as HF-I, for replication of phage $\mathrm{Q}_{\beta}$ RNA [45]. Hfq also controls the translation of the $\sigma$ factor gene $r p o S$ and the DNA repair gene mutS $[47,48]$. Our results indicate that a certain amount of Hfq protein exists in the cytosol, supposedly in association with the translation machinery, although $70 \%$ of Hfq is associated with the nucleoid. StpA, a putative homolog of H-NS protein, was first identified as a multicopy suppressor of a $t d^{\top}$ phenotype of phage T4 [46].

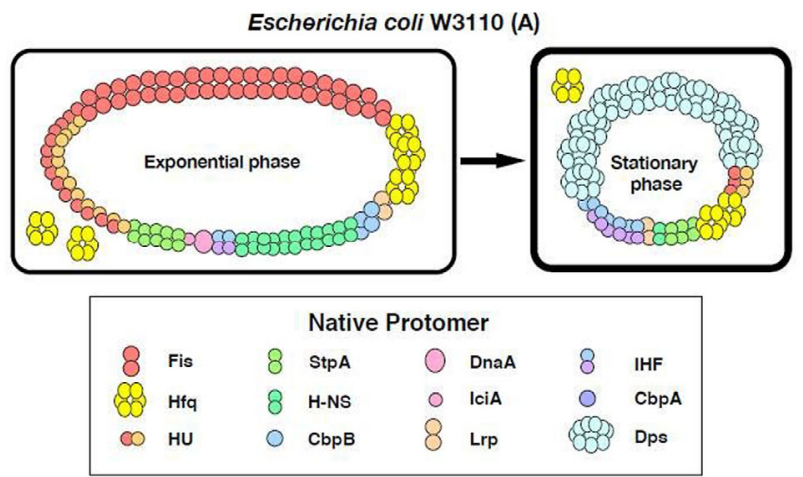

Figure 6 Possible models for the growth-phase dependent changes in the structure and protein composition of E. coli nucleoid. We have explained here the fundamental structure and the stress-induced structure of $E$. coli nucleoid present in exponential and stationary growth phases, respectively. This model was proposed based on various results shown in Figures 2-4 and the results published previously $(14,15,16,28,40,53,55,59,60)$. The major changes in $E$. coli cell entering into stationary (variations of cell shape/size, volume, cell wall, nucleoid and its structure and composition etc) growth phase are shown. Cell shape/size or cytoplasmic volume and cell wall composition of $E$. coli cells are decrease and increase, respectively, at stationary growth phase [16,27]. Because, in E. coli stationary phase, 4-5 layers of peptidoglycan, a cell wall component were found compared to only 2-3 in exponential phase are represented by outer thick (top right) and thin (top left) circles, respectively [27]. The top inside left and right circles represented the nucleoid organization state of exponential and stationary phase E. coli cells, respectively. Bottom panel represents the native protomeric forms (functional form) of 12-nucleoid associated proteins studies here (from left to right, $\mathrm{CbpB}$, DnaA, IciA and CbpA are monomer; Fis, HU, StpA, H-NS, Lrp and IHF are dimers; Hfq and Dps are found to be hexamers and dodecamers, respectively [27]). These proteins accumulation/synthesis level and their association with nucleoid compactness were varied between two distinct growth phases. Because, exponential phase nucleoid (top left panel inside circle) is less compacted than that of stationary phase (top right panel inside circle) was also seen in Figure 2. The percentage distribution ratios of nucleoid-associated proteins in $E$. coli were estimated from Western immunoblot analysis, after separation of cell lysates into nucleoid and cytosolic fractions by sucrose density gradient centrifugation. Intracellular concentrations of CbpA, DnaA, IciA and Lrp protein were previously estimated [27]. The intracellular concentrations of nucleoid-associated proteins in E. coli were converted into the number of molecules per cell. Each spot corresponds to 1,000 molecules per cell (the proteins of less than 1,000 molecules per cell are all shown as a single spot). All the nucleoid proteins are assumed to be associated with the DNA. The major components of exponential phase nucleoid are Fis, HU, H-NS, StpA and Hfq, while Dps occupies more than half of the stationary-phase nucleoid. In addition to the effect of DNA supercoiling, increase in cellular concentrations of Dps and IHF at stationary phase must be involved in growth phase-dependent nucleoid compaction in E. coli $[14,15,27,28,40,60]$.

The high sequence identity (58\%) between StpA and H-NS suggests that the two proteins perform overlapping functions. The association of H-NS and StpA on nucleoid fraction are almost $100 \%$ (Figure 5), but the cellular amounts of StpA is lower than H-NS in the cell can still have significant impact on DNA architecture [26]. It does seems likely not only that StpA can effectively replace (or assist) H-NS in its function as a repressor of transcription but also involved in the modulation of nucleoid compactness [5,49]. Our results are consistent with the results published previ- 
ously by Dame et al. [50], microscopic analyses reveals that StpA binds with plasmid DNA and make higher-order structure.

\subsection{Dps plays a crucial role in nucleoid compaction at stationary phase}

The Dps protein was first identified as a stress-induced protein and is known to form a dodecameric complex [41,42]. It binds to DNA without sequence specificity [26]. Cellular concentration of Dps is low ( 7,000 molecules per cell) in the exponential phase compared with other nucleoid proteins ( 60,000 molecules per cell for Fis, Hfq, HU). However, in the stationary phase, Dps becomes the most abundant protein (180,000 molecules per cell) [27]. Overexpression of Dps induced an intracellular crystalline structure in vivo and purified Dps proteins were co-crystallized with DNA [51,52]. The highly compacted nucleoids observed in stationary phase appear to have similar characteristics to a bio-crystal [40,53]. Therefore, here we conclude that the bacterial cells might protect their own nucleoids from various environmental stresses by tight compaction. Indeed, the $d p s$ mutant cells are very sensitive to environmental stresses [43,53]. Moreover, several mutational analyses demonstrated that the stationary phase specific tight compaction of the nucleoid required a protein $[28,40]$. The Dps protein is thus crucial for achieving higher order structures and for protecting various environmental stresses.

\section{Concluding remarks}

Here, we have discussed the structure and composition of $E$. coli nucleoid and its compactness under different growth phases. Although the 5 major proteins (Fis, HU, H-NS, StpA, and Hfq) of exponential-phase nucleoids may be fluctuated in expression under different conditions, they are up to $\sim 70 \%$ of the total nucleoid proteins [32,54-58]. However, it is difficult to speculate on the exact conformation of E. coli nucleoid especially at the stationary phase since there is insufficient information available in this field $[59,60]$. At this phase of growth, the cell physiology and metabolic activity alters dramatically and this leads to changes in physico-chemical properties of cell components. Study in stationary phase nucleoid is still in the early stage. Detailed comparative examination of the nucleoid structure and composition in stationary phase seems to be worth in future investigations.

This work was supported by Grants-in-Aid from the Ministry of Education, Science and Culture of Japan, and Core Research for Evolutional Science and Technology of Japan Science and Technology Corporation. The authors thank to Nobuyoki Fujita for valuable suggestion during manuscript preparation. Authors also thanks to Takeshi Mizuno and Naoki Goshima for gifts of the antibodies against $H-N S$ and $H U$, respectively.
1 Hecht RM, Taggart RT, Pettijohn DE. Size and DNA content of purified $E$. coli nucleoids observed by fluorescence microscopy. Nature, 1975, 253: 60-62

2 Pettijohn DE. Sinder RR. Structure of the isolated nucleoid. In: Nanninga N, eds. Molecular Cytology of Escherichia coli. London: Academic Press, 1985. 199-227

3 Hinnebusch B, Bendich AJ. The bacterial nucleoid visualized by fluorescence microscopy of cells lysed within agarose: comparison of Escherichia coli and Spirochetes of the genus Borrelia. J Bacteriol, 1997, 179: 2228-2237

4 Pettijohn DE. Structure and properties of the bacterial nucleoid. Cell, 1982, 30: 667-669

5 Pettijohn DE. Bacterial chromosome structure. Nucleic Acids Mol Biol, 1990, 4: 152-162

6 Pettijohn DE. The nucleoid. In: Neidhardt FC, eds. Escherichia coli and Salmonella. Cellular and Molecular Biology. Washington: ASM, 1996. 158-166

7 Schmid MB. More than just "histone-like" proteins. Cell, 1990, 63: $451-453$

8 Stonington OG, Pettijohn DE. The folded genome of Escherichia coli isolated in a protein-DNA-RNA complex. Proc Natl Acad Sci USA, 1971, 68: 6-9

9 Worcel A, Burgi E. On the structure of the folded chromosome of Escherichia coli. J Mol Biol, 1972, 71: 127-147

10 Woldringh CL. Nanninga N. Structure of the nucleoid and cytoplasm in the intact cell. In: Nenninga N, eds. Molecular Cytology of Escherichia coli. London: Academic Press, 1985. 161-197

11 Ghosh S, Mallick B, Nagaraja V. Direct regulation of topoisomerase activity a by nucleoid-associated protein. Nuclis Acids Res, 2014, 42: 11156-11165

12 Flashner Y, Gralla JD. DNA dynamic flexibility and protein recognition-differential stimulation by bacterial histone-like protein HU. Cell, 1988, 54: 713-721

13 Finkel SE, Johnson RC. The Fis protein: it's not just for DNA inversion anymore. Mol Microbiol, 1992, 6: 3257-3265

14 Goosen N. van de Putte P. The regulation of transcription initiation by integration host factor. Mol Microbiol, 1995, 16: 1-7

15 Ishihama A. Modulation of the nucleoid, the transcription apparatus and the translation machinery for stationary phase survival. Genes Cells, 1999, 4: 135-143

16 Talukder AA, Hossain MA, Yamada M, Ishihama A. Nucleoids dynamics in Escherichia coli: a growth phase dependent process. Bangladesh J Microbiol, 2006, 23: 81-88

17 Ohniwa RL, Morikawa K, Takeshita SL, Kim J, Ohta T, Wada C, Takeyasu K. Transcription-coupled nucleoid architecture in bacteria. Genes Cells, 2007, 12: 1141-1152

18 Xindan W, Llopis PM, Rudner DZ. Organization and segregation of bacterial chromosomes. Nat Rev Gent, 2013, 14: 191-203

19 Ball CA, Osuna R, Ferguson KC, Johnson RC. Dramatic changes in Fis levels upon nutrient upshift in Escherichia coli. J Bacteriol, 1992, 174: 8043-8056

20 Ditto MD, Roberts D, Weisberg RA. Growth phase variation of integration host factor level in Escherichia coli. J Bacteriol, 1994, 176: 3738-3748

21 Drlica K, Rouviere-Yaniv J. Histone-like proteins of bacteria. Microbiol Rev, 1987, 51: 301-319

22 Dürrenberger M, Bjornsti MA, Uetz T, Hobot JA, Kellenberger E. Intracellular localization of the histone like protein HU in Escherichia coli. J Bacteriol, 1988, 170: 4757-4768

23 Dürrenberger M, La Teana A, Citro G, Venanzi F, Gualerzi CO, Pon CL. Escherichia coli DNA-binding protein H-NS is located in the nucleoid. Res Microbiol, 1991, 142: 373-380

24 Pettijohn DE. Histone-like proteins and bacterial chromosome structure. J Biol Chem, 1988, 263: 12793-12796

25 Rouviere-Yaniv J, Yaniv M, Germond JE. Escherichia coli DNA-binding protein HU forms nucleosome-like structure with circular double-stranded DNA. Cell, 1979, 17: 265-274

26 Talukder AA, Ishihama A. Twelve species of the nucleoid-protein from Escherichia coli: sequence recognition specificity and 
DNA-binding affinity. J Biol Chem, 1999, 274: 33105-33113

27 Talukder AA, Iwata A, Nishimura A, Ueda S, Ishihama A. Growth phase-dependent variation in protein composition of the Escherichia coli nucleoid. J Bacteriol, 1999, 181: 6361-6370

28 Sato YT, Watanabe S, Kenmotsu T, Ichikawa M, Yoshikawa Y, Teramoto J, Imanaka T, Ishihama A, Yoshikawa K. Structural change of DNA induced by nucleoid proteins: growth phase-specific Fis and stationary phase-specific Dps. Biophys J, 2013, 105: 1037-1044

29 Talukder AA, Hiraga S, Ishihama A. Two types of localization of the DNA-binding proteins within the Escherichia coli nucleoid. Genes Cells, 2000, 5: 613-626

30 Jishage M, Ishihama A. Variation in RNA polymerase sigma subunit composition within different stocks of Escherichia coli W3110. J Bacteriol, 1997, 179: 959-963

31 Kornberg T, Lockwood A, Worcel A. Replication of the Escherichia coli chromosome with a soluble enzyme system. Proc Natl Acad Sci USA, 1974, 71: 3189-3193

32 Murphy LD. Zimmerman SB. Stabilization of compact spermidine nucleoids from Escherichia coli under crowded conditions: implication for in vivo nucleoid structure. J Struct Biol, 1997, 199: 321-335

33 Hiraga S, Ichinose C, Niki H, Yamazoe M. Cell cycle-dependent duplication and bidirectional migration of SeqA-associated DNA-protein complexes in E. coli. Mol Cell, 1998, 1: 381-387

34 Zimmerman SB. Studies on the compaction of isolated nucleoids from Escherichia coli. J Struct Biol, 2004, 147: 146-158

35 Cournac A, Plumbridge J. DNA looping in prokaryotes: experimental and theoretical approaches. J Bacteriol, 2013, 195: 1109-19

36 Jishage M, Ishihama A. Regulation of RNA polymerase sigma subunit synthesis in Escherichia coli: intracellular levels of $\sigma^{70}$ and $\sigma^{38}$. J Bacteriol, 1995, 177: 6832-6835

37 Broyles S, Pettijohn D. Interaction of the Escherichia coli HU protein with DNA. Evidence for formation of nucleosome-like structures with altered DNA helical pitch. J Mol Biol, 1986, 187: 47-60

38 Åkerlurd T, Nordström K, Bernander R. Analysis of cell size and DNA content in exponentially growing and stationary-phase batch cultures of Escherichia coli. J Bacteriol, 1995, 177: 6791-6797

39 Weitao T, Nordström K, Dasgupta S. Mutational suppression of $m u k B$ and $s e q A$ phenotypes might arise from their opposing influences on the Escherichia coli nucleoid structure. Mol Microbiol, 1999, 34: 157-168

40 Kim J, Yoshimura SH, Hizume K, Ohniwa RL, Ishihama A, Takeyasu K. Fundamental structural units of the Escherichia coli nucleoid revealed by atomic force microscopy. Nucleic Acids Res, 2004, 32: 1982-1992

41 Almirón M, Link AJ, Furlong D, Kolter R. A novel DNA binding protein with regulatory and protective roles in starved Escherichia coli. Genes Dev, 1992, 6: 2646-2654

42 Grant RA, Filman DJ, Finkel SE, Kolter R, Hogle JM. The crystal structure of Dps, a ferritin homolog that binds and protects DNA. Nat Struct Biol, 1998, 5: 294-303

43 Kajitani M, Ishihama A. Identification and sequence determination of the host factor gene for bacteriophage $Q_{\beta}$. Nucleic Acids Res, 1991, 19: 1063-1066

44 Kajitani M, Kato A, Wada A, Inokuchi Y, Ishihama A. Regulation of the Escherichia coli hfq gene encoding the host factor for phage $\mathrm{Q}_{\beta}$. J Bacteriol, 1994, 176: 531-534

45 Skarstad K, Thony B, Hwang DS, Kornberg A. A novel binding protein of the origin of the Escherichia coli chromosome. J Biol Chem, 1993, 268: 5365-5370

46 Zhang Z, Belfort M. Nucleotide sequence of a newly identified Escherichia coli gene, stpA, encoding an H-NS-like protein. Nucleic Acids Res, 1992, 20: 6734

47 Muffler A, Fischer D, Hengge-Aronis R. The RNA-binding protein HF-I, known as a host factor for phage $\mathrm{Q}_{\beta}$ RNA replication, is essential for rpoS translation in Escherichia coli. Genes Dev, 1996, 10: 1143-1151

48 Schuppli D, Miranda G, Tsui HC, Winkler ME, Sogo JM, Weber H. Altered 3'-terminal RNA structure in phage $\mathrm{Q}_{\beta}$ adapted to host factor-less Escherichia coli. Proc Natl Acad Sci USA, 1997, 94: 10239-10242

49 Zhang Z, Rimisky S, Reaban ME, Buc H, Belfort M. Escherichia coli protein analogs StpA and H-NS: regulatory loops, similar and disperate effects on nucleoid acid dynamics. EMBO J, 1996, 15: 1340-1349

50 Dame RT, Luijsterburg MS, Krin E, Bertin PN, Wagner R, Wuite GJ. DNA bridging: a property shared among H-NS-like proteins. J Bacteriol, 2005, 187: 1845-1848

51 Frenkiel-Krispin D, Levin-Zaidman S, Shimoni E, Wolf SG, Wachtel EJ, Arad T, Finkel SE, Kolter R, Minsky A. Regulated phase transitions of bacterial chromatin: a non-enzymatic pathway for generic DNA protection. EMBO J, 2001, 20: 1184-1191

52 Wolf SG, Frenkiel D, Arad T, Finkel SE, Kolter R, Minsky A. DNA protection by stress-induced biocrystallization. Nature, 1999, 400: 83-85

53 Ohniwa RL, Muchaku H, saito S, Wada C, Morioka K. Atomic force microscopy analysis of the role of major DNA-binding proteins in organization of the nucleoid in Escherichia coli. PLoS One, 2013, 8: e72954

54 Martinez A. Kolter R. Protection of DNA during oxidative stress by the nonspecific DNA-binding protein Dps. J Bacteriol, 1997, 179: 5188-5194

55 Talukder AA, Survival and death in bacteria. In: Yamada M, eds. Structure and Composition of Escherichia coli Nucleoid. Kerala: Research Signpost, 2005, 2: 77-101

56 Murphy LD, Zimmerman SB. Isolation and characterization of spermidine nucleoids from Escherichia coli. J Struct Biol, 1997, 199: 336-346

57 Yamazaki KI, Nagata A, Kano Y, Imamoto F. Isolation and characterization of nucleoid proteins from Escherichia coli. Mol Gen Genet, 1984, 196: 217-224

58 Yasuzawa K, Hayashi N, Goshima N, Kohno K, Imamoto F, Kano Y. Histone-like proteins are required for cell growth and restraint of supercoils in DNA. Gene, 1992, 122: 9-14

59 Meyer AS, Grainger DC. The Escherichia coli nucleoid in stationary phase. Adv Appl Microbiol, 2013, 83: 69-86

60 Ishihama A. The nucleoid: an overview. In: Neidhardt FC, eds. Escherichia coli and Salmonella. 2nd ed. Washington: ASM press, 2009

Open Access This article is distributed under the terms of the Creative Commons Attribution License, which permits any use, distribution, and reproduction in any medium, provided the original author(s) and source are credited. 